\section{Sun and water in the greenhouse}

SIR - In their review article on the greenhouse effect ${ }^{1}$, Hansen and Lacis stated that measurements of changes in solar diameter limit solar brightness variations to a few tenths of a per cent, citing an article $^{2}$ by one of us (R.I.G.) in support of this estimate. But the article does not support their statement: it actually states that solar diameter changes would constrain solar brightness variations only to a limit of $10 \%$.

The second source for limits on solar changes cited by Hansen and Lacis is a calculation based on the implausible assumption that magnetic fields of the order of a million gauss exist at the base of the solar convective zone. This assumption is unnecessary as fields of 3-5 kilogauss are sufficient to explain the strength of the fields erupting on the Sun's surface; and it is also extremely improbable, as a million-gauss field at the base of the convective zone would create violently disruptive buoyancy forces and magnetic stresses in the Sun's interior. There is no observational or theoretical evidence to preclude changes of up to $1-2 \%$ in the Sun's brightness over century timescales, or linear trends of the order of $0.1 \%$ per decade.

Hansen and Lacis note that the climate impact of such changes is comparable to the impact of the greenhouse effect. They also note, contrary to the thrust of their main conclusion, that "measurements of solar irradiance during the next decade or two are crucial for determination of longterm climate trends".

RONALD I. GILLILAND

Space Telescope Science Institute,

Baltimore,

Maryland 21218, USA

Department of Earth Sciences,

ROBERT JASTROW

Fairchild Science Center,

Dartmouth College,

Hanover,

New Hampshire 03755, USA

Enrico Fermi Institute,

University of Chicago,

Chicago,

IIlinois 60637, USA

SIR - Hansen and Lacis' criticize my arguments ${ }^{+}$concerning the possible role of cumulus convection in providing a strong negative feedback. Contrary to their suggestion, our calculations do include "moisture detrainment, cirrus anvils, large-scale dynamics and other processes". We recognized that water vapour in the upper troposphere (above about 7 $\mathrm{km}$ ) is, molecule for molecule, much more important to the temperature of the Earth than water vapour near the surface. Thus, reductions in water vapour at these levels might more than compensate for increases near the ground.

The evidence cited by Hansen and Lacis against our argument is irrelevant. Oort and Rasmussen ${ }^{5}$ analysed data for humidity below about $6 \mathrm{~km}$; Raval and Ramanathan ${ }^{6}$ looked at vertically integrated water vapour which is dominated by water vapour near the ground. Neither relate to upper-level water vapour. Even Hansen et al. state in a recently published letter" "it has been argued that the upper troposphere could become drier as the lower atmosphere becomes moister. Thus, reliable evaluation of the water vapour feedback requires monitoring of water vapour, especially in the upper troposphere, in conjunction with climate changes."

RICHARD S. LINDZEN Massachusetts Institute of Technology, Cambridge,

HANSEN AND LACIS REPLY - Both Gilliland $e t a l$. and Lindzen in their arguments fail to see the forest for the trees.

Lindzen argues that moist (cumulus) convection, expected to increase with global warming, dries the upper troposphere, thus causing a negative climate feedback. Global climate models, some incorporating cumulus subsidence drying, all yield the opposite result: greenhouse warming increases the absolute humidity in the upper (and lower) troposphere. Lindzen $^{4}$ does not present calculations including moisture detrainment into cirrus anvils, large-scale dynamics and other important processes. But his arguments create the impression of a complex disagreement among theorists.

A simple acid test is provided by the real world: does the summer increase of moist convection dry the upper troposphere? Radiosonde data indicate summertime moistening, but Lindzen dismisses these as inaccurate. Precise profiles of water vapour have been measured by satellite : these show summertime moistening of the upper troposphere at all latitudes. Measurements of the Earth radiation budget ${ }^{t}$, which take into account the effect of the entire atmospheric column, independently show that greenhouse warming is largest in regions of moist convection, precisely where Lindzen's 'theory' predicts a minimum. Our call for global monitoring of all major climate forcings and feedbacks ${ }^{7}$ is intended to quantify causes of climate change. We did not intend to provide evidence for a negative water vapour feedback which, in fact, is excluded by existing data.

Our discussion of solar variability referred to a report" arguing that reductions of greenhouse-gas emissions "could
Massachusetts 02139, USA turn out to be unnecessary or even harmful" because solar variations may cancel greenhouse warming. We pointed out that one cannot simultaneously assume high climate sensitivity to solar change and low sensitivity to greenhouse-gas changes. The simplest way to look at mechanisms for climate change is to compare the forcings. This procedure shows that the Sun's irradiance must decrease by $2 \%$ to cancel the anthropogenic greenhouse forcing that will exist in the first half of next century. There is no evidence for such a large long-term solar decline. Satellite data show a net change much less than $0.1 \%$ since 1978 (ref. 10); observations corrected for atmospheric transparency changes yield an upper limit of a few tenths of a per cent this century" ; some solar-type stars vary by several tenths of a per cent ${ }^{32}$.

The only other evidence we cite on solar variability is the upper limit on solar diameter changes during the past two centuries. These data and Sofia's calculations (we do not use Gilliland's) place an upper limit of a few tenths of a per cent on solar variations ${ }^{13.14}$. We agree that the result depends on the solar model used, and thus diameter measurements alone add little to the above limits on solar variability. But these data certainly provide no evidence for large changes in solar irradiance.

We stated that "the possibility of a decline of solar irradiance by $2 \% \ldots$ has not been ruled out categorically". But there is no evidence for such an impending large decline. Thus our conclusion, "Given available scientific evidence, it would be foolish to base greenhouse policy on the hope that solar variability will somehow counteract greenhouse warming", seems to hit the nail on the head.

JAMES E. HANSEN ANDREW A. LACIS

NASA Goddard Institute for

Space Studies,

2880 Broadway, New York,

New York 10025, USA

1. Hansen, J. E. \& Lacis, A. A. Nature 346, 713-719 (1990)

2. Gilliland, R. I. Astrophys. J. 253, 399-405 (1982)

3. Endal, A. S., Sofia, S. \& Twigg, L. W. Astrophys. J. 290 $748-757$ (1985).

4. Lindzen, R. S. Bull. Met. Soc. Am. 71, 288-289 (1990)

5. Oort, A. H. \& Rasmusson, E. M. Prof. Pap. NOAA 14, 323 (1971)

6. Raval, A. \& Ramanathan, V. Nature 342, 758-761 1989)

. Hansen, J., Rossow, W. \& Fung, I. Issues Sci. Tech. 7, no. 1. $62-69(1990)$

8. Rind, D.. Chiou, E.-W., Chu, W.. Larsen, J., Oltmans, S. Lerner, J McCormick, M. P. \& McMaster, L. Nature $\mathbf{3 4 9}$ $500-503(1991)$

9. Seite, F., Jastrow, R. \& Nierenberg, W. Scientific Perspectives on the Greenhouse Problem (Marshall Institute, Washington, DC, 1989).

10. Willson, R. C. \& Hudson, H. S. Nature 332, 810-812 (1988).

11. Hoyt, D. V. Rev. geophys. Space Phys. 17, 429--458 (1979)

12. Radick, R. R., Lockwood, G. W. \& Baliunas, S. L. Science 247, 39-44 (1990)

13. Sofia, S. Geophys. Monogr. Ser. 29, 202-206 (1984).

14. Endal, A. S., Sofia, S. \& Twigg, L. W. Astrophys. J. 290 748-757 (1985) 